\title{
Medical approach to urinary retention after vaginal hysterectomy
}

\author{
(1) ILKER GÜLBAȘARAN ${ }^{1}$, (1) AYTEKIN TOKMAK² \\ 1Salihli State Hospital, Clinic of Gynaecology and Obstetrics, Manisa, Turkey \\ 2Zekai Tahir Burak Women's Health Training and Research Hospital, Clinic of Gynaecology and Obstetrics, Ankara, Turkey
}

\section{ABSTRACT}

A 65 years old women presented with grade 3 descensus, grade 4 cystocele, grade 2 rectocele. The patient had no complaints of urinary incontinence. She underwent vaginal hysterectomy, colporrhaphy anterior, colporrhaphy posterior and sacrospinous fixation operations. On the postoperative first day, after removal of the catheter, the patient developed glob vesicale. The urinary retention was thought to be due to oedema secondary to surgical operation and urinary antiseptic and anti-inflammatory treatment was started. The catheter was removed 5 days later but re-inserted due to urinary retention. Alpha-adrenergic blocker (doxazosin) was added to the medical treatment. After 3 days, the catheter was removed, and spontaneous urination was observed and doxazosin treatment was stopped.

Keywords: Alpha-adrenergic blocker; urinary retention; vaginal hysterectomy

\section{INTRODUCTION}

Hysterectomy is one of the most widely used major surgical procedures in gynaecology practice. ${ }^{1}$ Patient's anatomy is important as well as the experience of the surgeon in the choice of laparotomic, vaginal or laparoscopic approaches. Vaginal hysterectomy is the most preferred method in the cases of prolapsus. The advantages of vaginal hysterectomy are lower rates of infection, fewer complications, less pain, shorter hospital stay, shorter operating time and better cosmetic outcome. Micturition difficulty and urinary retention are common complications after abdominal or vaginal hysterectomy.

There are various medications for treatment of postoperative urinary retention, including cholinergicagents, anticholinesterase agents, alpha-blockers, sedatives and prostaglandin., 2,3

Neostigmine is an acetylcholinesterase inhibitor or anticholinesterase agent. It causes accumulation of acetylcholine around the cholinergic nerve terminals. ${ }^{4}$ Urinary bladder contraction is critically dependent on acetylcholine-induced stimulation of contractile muscarinic receptors on the smooth muscle (detrusor) of the urinary bladder., Intramuscular injection of neostigmine is only effective in $70 \%$ of patients, and it is associated with many side effects such as bradycardia, bronchoconstriction, increased secretions, nausea, and vomiting. ${ }^{7}$

Alpha-adrenergic receptors are located in the bladder neck and proximal urethra, and blocking these receptors with alphablockers may facilitate urine flow and prevent postoperative urinary retention. ${ }^{8}$

In this report, we aimed to present the medical management of the patient who underwent vaginal hysterectomy, colporrhaphy anterior, colporrhaphy posterior and sacrospinous fixation and developed urinary retention after catheter removal. 


\section{CASE REPORT}

A 65-year-old female patient (gravida: 3, parity: 2, abortus: 1) was admitted to the outpatient clinic with the complaint of uterine prolapse. The patient was prepared for operation due to grade 3 descensus, grade 4 cystocele, grade 2 rectocele on vaginal examination. The patient had no complaints of urinary incontinence. The patient's medical history revealed that she had been receiving medical treatment for hypertension and had been postmenopausal for 20 years. Preoperative complete blood count $(\mathrm{Hb}=12.3 \mathrm{~g} / \mathrm{dL})$, complete urinalysis and routine biochemical values were normal. In transvaginal ultrasonography, the uterus was atrophic and the endometrial thickness was $3 \mathrm{~mm}$ and there was no adnexal pathology. The patient underwent vaginal hysterectomy, colporrhaphy anterior, colporrhaphy posterior and sacrospinous fixation operations under spinal anaesthesia. After the surgery, a catheter into the bladder, and a vaginal pack were placed. On the postoperative first day, the patient had a haemoglobin value of $10.8 \mathrm{~g} / \mathrm{dL}$, and her vaginal pack and catheter were removed. After removal of the catheter, the patient developed globe vesicale (distended bladder), therefore foley catheter was inserted again. The urinary retention was thought due to oedema secondary to surgical operation and urinary antiseptic and anti-inflammatory treatment was started and urine culture was performed. The urine culture was negative and the catheter was removed 5 days later but reinserted due to urinary retention. Alpha-adrenergic blocker (doxazosin 1x8 $\mathrm{mg} /$ day) was added to the medical treatment. After 3 days, the catheter was removed, and spontaneous urination was observed and doxazosin treatment was stopped. The residual urine volume was $30 \mathrm{cc}$. The patient was discharged on the $11^{\text {th }}$ postoperative day. Written informed consent was obtained from the patient for publication of this case report.

\section{DISCUSSION}

Vaginal hysterectomy with or without colporrhaphy is one of the most common surgical procedures for the treatment of symptomatic pelvic organ prolapse. ${ }^{9}$ In the literature, the incidence of postoperative urinary retention after any vaginal prolapse surgery is reported to be between $6 \%$ and $29 \% .^{10-12}$ Known risk factors for urinary retention after vaginal prolapse surgery include advanced age, high-grade cystocele, severe intraoperative blood loss, levator and Kelly plication, postoperative pelvic hematoma, and removal of the catheter in a short time. ${ }^{12,13}$ In a study by Leung at al. ${ }^{1}$, it was found that postoperative urinary retention was more common in women older than 63 years. In our case, we think that the presence of advanced age and high-grade cystocele may be risk factors for urinary retention.
However, there is no consensus regarding the time of urinary catheter removal after vaginal propapsus surgery. In the literature, there was no significant difference in the rates of urinary retention between the removal of urinary catheter on postoperative day 1 and day 3 in some studies. ${ }^{14}$ However, a randomized controlled trial by Hakvoort et al. ${ }^{15}$ showed a significant difference in urinary retention between day 1 and day 5 catheter removal (recateterization rate 9-40\%).

The longer the duration of catheterization, the greater the incidence of urinary tract infection and the duration of hospital stay. For this reason, we usually remove the urinary catheter on the 1st postoperative day. In the literature, the incidence of urinary retention after vaginal hysterectomy was $6-27 \%$, while in our series we found $1.49 \%(1 / 67)$.

It is known that there are alpha-adrenergic receptors in urinary tract especially along the bladder neck and urethra. ${ }^{16}$ Stimulation of these receptors causes an increase in smooth muscle contraction and bladder neck resistance, whereas alphaadrenergic blockage causes smooth muscle relaxation and a decrease in bladder output resistance. ${ }^{17}$ For many years, alphaadrenergic blockers have been used for the treatment of benign prostatic hypertrophy to reduce resistance to the bladder neck and to relieve the flow of urine.

Livne et al. ${ }^{8}$ suggested that alpha-blockers should be used prophylactically in order to prevent urinary retention after abdominal or vaginal hysterectomy. The incidence of postoperative urinary retention in our hospital is quite low, because of this we do not use prophylactic alpha-adrenergic blockers.

In conclusion, urinary retention is common after vaginal hysterectomy. The course and clinical management of this process carry some difficulties for both the surgeon and the patient. We think that medical therapies such as alpha-adrenergic blockers may be useful in providing spontaneous micturition in patients who have no additional complication and palliative methods is not successful.

\section{ETHICS}

Informed Consent: Written informed consent was obtained from the patient for publication of this case report.

Peer-review: Externally peer-reviewed.

\section{DISCLOSURES}

Conflict of Interest: No conflict of interest was declared by the authors.

Financial Disclosure: The authors declared that this study received no financial support. 


\section{REFERENCES}

1. Leung PL, Tsang SW, Yuen PM, et al. An audit on hysterectomy for benign diseases in public hospitals in Hong Kong. Hong Kong Med J 2007; 13: 187-93.

2. Buckley BS, Lapitan MC. Drugs for treatment of urinary retention after surgery in adults. Cochrane Database Syst Rev 2010: CD008023. doi: 10.1002/14651858.CD008023.pub2

3. Taylor P. Anticholinesterase agents. In: Brunton LL, Chabner BA, Knollmann BC, editors. Goodman and Gilman's The Pharmacological Basis of Therapeutics. 12th ed. New York: McGraw-Hill; 2011; 123775.

4. Senapathi TGA, Wiryana M, Subagiartha IM, et al. Effectiveness of intramuscular neostigmine to accelerate bladder emptying after spinal anesthesia. Ther Clin Risk Manag 2018; 14: 1685-9.

5. Nakahara T, Kubota Y, Sakamoto K, Ishii K. The role of cholinesterases in rat urinary bladder contractility. Urol Res 2003; 31: 223-6.

6. Hegde SS, Eglen RM. Muscarinic receptor subtypes modulating smooth muscle contractility in the urinary bladder. Life Sci 1999; 64: 419-28.

7. Li YS. Treatment of postpartum urinary retention with acupuncture: report of 44 cases. China Health Industry. 2012; 9: article 171.

8. Livne PM, Kaplan B, Ovadia Y, Servadio C. Prevention of posthysterectomy urinary retention by alpha-adrenergic blocker. Acta Obstet Gynecol Scand 1983; 62: 337-40.

9. Chong C, Kim HS, Suh DH, Jee BC. Risk factors for urinary retention after vaginal hysterectomy for pelvic organ prolapse. Obstet Gynecol Sci 2016; 59: 137-43.
10. Fernandez RS, Griffiths RD. Duration of short-term indwelling catheters: a systematic review of the evidence. J Wound Ostomy Continence Nurs 2006; 33:145-53.

11. Ghezzi F, Uccella S, Cromi A, et al. Surgical treatment for pelvic floor disorders in women 75 years or older: a single-center experience. Menopause 2011; 18: 314-8.

12. Hakvoort RA, Dijkgraaf MG, Burger MP, Emanuel MH, Roovers JP. Predicting short-term urinary retention after vaginal prolapse surgery. Neurourol Urodyn 2009; 28: 225-8.

13. Segev Y, Auslender R, Lissak A, Lavie O, Abramov Y. Symptomatic pelvic hematoma following transvaginal reconstructive pelvic surgery: incidence, clinical presentation, risk factors, and outcome. Eur J Obstet Gynecol Reprod Biol 2010; 153: 211-4.

14. Alonzo-Sosa JE, Flores-Contreras JT, Paredes-Canul M. Method for transurethral catheterization for 1-3 days for pelvic floor relaxation in the postoperative period. Ginecol Obstet Mex 1997; 65: 455-7.

15. Hakvoort RA, Elberink R, Vollebregt A, Ploeg T, Emanuel MH. How long should urinary bladder catheterisation be continued after vaginal prolapse surgery? A randomised controlled trial comparing short term versus long term catheterization after vaginal prolapse surgery. BJOG 2004; 111: 828-30.

16. Andersson KE. Mode of action of a1-adrenoceptor antagonists in the treatment of lower urinary tract symptoms. Br J Urol 2000; 85: 12. doi: 10.1046/j.1464-410X.2000.00059.x

17. Sullivan J, Abrams P. Alpha-adrenoceptor antagonists in neurogenic lower urinary tract dysfunction. Urology 1999; 53: 21-8. 